
\title{
$\begin{array}{ll}\text { Research Square } & \begin{array}{l}\text { Preprints are preliminary reports that have not undergone peer review. } \\ \text { They should not be considered conclusive, used to inform clinical practice, } \\ \text { or referenced by the media as validated information. }\end{array}\end{array}$ \\ The Employment Effect Of Chinese Enterprises Embedded In The Global Environmental Value Chain
}

\section{Shuhong Wang}

Shandong University of Finance and Economics

\section{Hanxue Chen}

Ocean University of China - Laoshan Campus: Ocean University of China

Kedong Yin ( $\nabla$ yinkedong1633@163.com )

Shandong University of Finance and Economics

\section{Research Article}

Keywords: Global environmental value chain, Employment, Female employment, Enterprise, Influence mechanism

Posted Date: June 8th, 2021

DOI: https://doi.org/10.21203/rs.3.rs-512494/v1

License: (c) (i) This work is licensed under a Creative Commons Attribution 4.0 International License. Read Full License 


\title{
The Employment Effect of Chinese Enterprises Embedded in the
}

\section{Global Environmental Value Chain}

\author{
Shuhong Wang ${ }^{a}$, Hanxue Chen ${ }^{\mathrm{b}}$, Kedong Yin ${ }^{\mathrm{a}}$ \\ a Institute of marine economy and management, Shandong University of Finance \\ and Economics, Jinan 250220, P. R. of China. \\ b School of Economics, Ocean University of China, Qingdao, 266100, P. R. of \\ China
}

\begin{abstract}
The employment effect of enterprises embedded in global value chains has important theoretical value, but existing research has ignored the impact of cross-border pollution transfer on employment under the division of labor system within the value chain. This study constructs a global environmental value chain (GEVC) analysis framework to combine economic and environmental issues and establishes a theoretical model to discuss the impact of the degree of enterprise embeddedness in the GEVC on employment. Using 2000-2006 data from the China Industry Business Performance and China Customs databases, the study finds that an increase in the degree of enterprise embeddedness has a significant inhibitory effect on employment, especially for female laborers, lower-skilled laborers, state-owned enterprises, private enterprises, and enterprises in the eastern region. The research also shows that the cost increase effect enhances the negative effect of increased GEVC embeddedness on employment, while the innovation promotion effect and the foreign direct investment effect serve to mitigate the negative effect. The results provide a reference for developing countries seeking to effectively protect people's livelihood and employment while achieving a leap in the division of labor along the green value chain.
\end{abstract}

Keywords: Global environmental value chain; Employment; Female employment; Enterprise; Influence mechanism

\section{Introduction}

For more than 40 years since the reform and opening-up of its economy, China has actively integrated into the division of labor system of the global value chain; owing to its low cost of labor and resource endowments, the country has gr adually become the world's second largest economy and a global manufacturing center. The division of labor system of the global value chain is characterized by value added, which has transformed the division of labor of the traditional international trade, characterized by the exchange of final products; it has also profoundly affected

\footnotetext{
* Corresponding author. E-mail address: yinkedong1633@163.com (K. Yin).
} 
the pattern and reform direction of the labor market. China is the most populous country in the world, and the resolution of the country's employment issues is directly related to its economic development, social stability, and standard of living for the general population. The report from the 19th National Congress of the Communist Party of China clearly states that it is necessary to adhere to the employment priority strategy and proactive employment policy to achieve higher quality and fuller employment. With the deepening of China's division of labor within the global value chain and the increasing pressure on employment, it is becoming more important to accurately consider the relationship between value chain embeddedness and employment.

Most studies have shown that global value chain embedding has significantly improved the scale and quality of employment in developing countries (Kaplan et al., 2018; Mangla et al., 2018; Amare et al., 2019; Fei et al., 2020; Wang et al., 2021). Reijnders and De Vries (2018) found that developing countries embedded in global value chains are mainly engaged in labor-intensive processing and assembly links, thus absorbing a large amount of surplus labor. Wang et al. (2019a) showed that although the rapid economic growth of China and India has increased labor costs, the impact of rising labor costs on the value chain will be offset by the income effect, thereby increasing the share of labor factors in China and India in the division of labor within the value chain. By contrast, some scholars have indicated that there is no evidence that participation in the global value chain improves the employment level of developing countries (Pahl \& Timmer, 2020). Others have noted that multinational companies are undermining their positive impact on job creation by investing in higher levels of intelligent and automated production equipment (Narula, 2019). However, there is still no consensus on the impact of global value chain embedding on employment, and further research is needed.

With the continuous evolution of the division of labor within the value chain and the environment and the exploitation of resources for economic growth, the subject of cross-border pollution transfers has started to generate more interest (Li \& Zhou., 2017; Li et al., 2019; Wang et al., 2019b). Meng et al. (2018) found that increasingly complex supply chains are distributing energy-intensive industries and their $\mathrm{CO}_{2}$ emissions to developing countries such as China and Vietnam, and this trend may seriously undermine the efforts of the international community to reduce global carbon emissions. Lopez et al. (2019) found that each additional dollar of value added by the subsidiaries of American multinational corporations operating overseas emits more $\mathrm{CO}_{2}$ than domestic production, and only $8 \%$ of the carbon is returned to the U.S. in the form of virtual carbon and reflected in the country's final consumption. Enterprises participating in the division of labor within the global value chain may gain a labor transfer effect and employment promotion. However, if embedding in the global value chain increases an enterprise's environmental governance costs, this could reduce its input into labor factors, and the health risks 
from exposure to environmental pollution may prompt workers to shift to other industries (Masso \& Vahter, 2019; Chang et al., 2019). Therefore, when studying the employment effect embedded in global value chains, ignoring the impact of pollution transfer may lead to unreliable conclusions.

Based on this, this study proposes the concept of the "global environmental value chain" (GEVC) and empirically examines the impact of enterprises' embeddedness in the GEVC on employment from the micro-level by constructing an method to account for the enterprise' embeddedness within global value chains considering environmental factors. The study finds that with the continuous improvement in the degree of enterprise embeddedness in the GEVC, the number of laborers employed has decreased significantly, and an increase in enterprises' export intensity can enhance their ability to absorb labor. The negative effect of GEVC embedding on employment is more pronounced for female employees and low-skilled employees. The increase in GEVC embedding of state-owned and private enterprises, as well as enterprises in China's eastern region, has suppressed enterprises' demand for labor, while the impact of the embeddedness of foreign-funded enterprises and that of enterprises located in the central and western regions are not significant. Further analysis shows that embeddedness in the GEVC affects the scale of employment through three channels, namely, the cost increase effect, the innovation promotion effect, and the foreign direct investment effect.

Compared with the existing literature, the contributions of this study are mainly from the following aspects. First, the existing research on the impact of global value chain embedding on employment ignores the problem of cross-border pollution transfer, which is a serious gap as the governance costs and health risks caused by pollution transfer are likely to affect the demand and supply of labor. This study combines the concepts of ecological footprint and ecological compensation with the most cutting-edge, firm-level global value chain embeddedness measurement method to determine the economic benefits and environmental costs of enterprises integrating into the global value chain, that is, the degree of enterprises' embeddedness in the GEVC. It studies the relationship between GEVC embedding and employment and uses a variety of methods to control for endogeneity. This approach is conducive to a more accurate assessment of the employment effects of enterprises' embedding in the value chain, and provides a reliable reference for developing countries to maintain the stability of the labor market.

Second, this study also compares and analyzes the differences in the employment impact of GEVC embedding and traditional export trade, the impact of GEVC embedding on laborers of different genders and with different types of skills, and the embedding of enterprises under different forms of ownership and in different regions. The differences in the impact of the GEVC on the level of employment in these heterogeneous cases provides theoretical support for the 
precise implementation of the policy of "stabilizing growth and securing employment" in developing countries.

Third, this paper examines the impact mechanism of GEVC embedding on employment by analyzing three channels: the cost increase effect, the innovation promotion effect, and the foreign direct investment effect. This helps reveal the in-depth mechanism of the impact of enterprise embeddedness on employment and provides possible path support for improving the relationship between GEVC embedding and employment.

The rest of this paper is structured as follows. Section 2 presents the theoretical model. Section 3 introduces the index measurement and model setting. Section 4 describes the empirical analysis. Section 5 presents the analysis of the influence mechanism. Section 6 provides concluding remarks and presents implications for policy.

\section{Theoretical model}

Based on the theoretical analysis framework of Feenstra and Hanson (1996) and Antweiler et al. (2001), this paper builds a labor demand model under the GEVC. In the model, we assume that there are only two countries in an open economy - one is a developed country and the other is a developing country. The developing country uses two production factors, $K$ and $L$, to produce two products, $X$ and $Y$, where the marginal returns of $K$ and $L$ are $r$ and $w$, respectively. The production process of product $X$ can be decomposed into a continuous intermediate product $Z, Z \in[0,1]$, while product $Y$ is independently produced by the developing country for domestic sales and export. Assuming that the developing country mainly produces intermediate product $Z$, which is pollution-intensive in the production process of product $X$, and $Y$ is the benchmark unit of pricing, the relative price of intermediate product $Z$ in the domestic market is $P$.

It is assumed that pollutant emissions $M$ (undesirable output) are generated by intermediate product $Z$ during the production process, and product $Y$ is a clean product with no undesirable outputs from its production process. Given the existence of government environmental regulatory policies, the potential outputs are set at a $\theta$ ratio of undesirable outputs. In the case that the production function is a Cobb-Douglas function with constant returns to scale, the desirable and undesirable outputs of intermediate product $Z$ are, respectively:

$$
Z=A(1-\theta) K^{\alpha} L^{1-\alpha}
$$

$$
M=e(\theta) A K^{\alpha} L^{1-\alpha}
$$

where $e(\theta)$ is the decreasing function of clean technology and undesirable outputs, expressed as: 


$$
e(\theta)=\frac{1}{A_{c}}\left(1 \frac{136)^{\frac{1}{\beta}}}{137} \quad 0<\beta<1\right.
$$

It is assumed that the influence function of developing countries' embedding in the GEVC on undesirable output $M$ is $w(\varphi)$, and $\varphi$ is the variable of the degree of enterprise embeddednessin the GEVC. Therefore, under the condition of embedding in the GEVC, the undesirable outputs and desirable outputs of intermediate product $\mathrm{Z}$ are:

$$
\begin{aligned}
& M=\frac{1}{A_{c}}(1-\theta)^{\frac{1}{\beta}} A K^{\alpha} L^{1-\alpha} w(\varphi) \\
& Z=A_{c}^{\beta} w(\varphi)^{-\beta} M^{\beta}\left(A K^{\alpha} L^{1-\alpha}\right)^{1-\beta}
\end{aligned}
$$

We assume that the government levies a tax, $t$, on unit pollution emissions, and after considering the level of clean technology, the government's carbon $\operatorname{tax} T$ can be expressed as:

$$
T=t A_{c} M
$$

It is assumed that $C^{f}(w, r)$ is the unit production cost when the potential output is $F$. Therefore, the optimal production decision for the enterprise embedded in the GEVC is to select the potential output and the optimal pollution emission level so that the unit production $\operatorname{cost}$ of $Z$ is minimized:

$$
\begin{gathered}
\eta^{*}=\min \left(C^{f}(w, r) K^{\alpha} L^{1-\alpha}+t A_{c} M\right) \\
\text { s.t } A_{c}^{\beta} w(\varphi)^{-\beta} M^{\beta}\left(A K^{\alpha} L^{1-\alpha}\right)^{1-\beta}=1
\end{gathered}
$$

The first-order condition of cost minimization can be obtained by constructing a Lagrange function as follows:

$$
\begin{aligned}
& C^{f}(w, r)=\lambda A_{c}^{\beta} w(\varphi)^{-\beta} M^{\beta}(1-\beta)\left(A K^{\alpha} L^{1-\alpha}\right)^{-\beta} \\
& \mathrm{t} A_{c}=\lambda A_{c}^{\beta} w(\varphi)^{-\beta} M^{\beta} \beta\left(A K^{\alpha} L^{1-\alpha}\right)^{1-\beta}
\end{aligned}
$$

By dividing Equation (9) and Equation (10), we obtain:

$$
\frac{C^{f}(w, r)}{t A_{c}}=\frac{M(1-\beta)}{\beta\left(A K^{\alpha} L^{1-\alpha}\right)}
$$

Assuming that the market is perfectly competitive, the profit of intermediate product $\mathrm{Z}$ is 0 :

$$
\pi=p Z-C^{f}(w, r) A K^{\alpha} L^{1-\alpha}-t A_{c} M=0
$$

Substituting the first-order condition into Equation (12), the following equation can be solved: 


$$
Z=\frac{t A_{c} M}{\beta p}
$$

Next, by substituting the above equation into Equation (4), we obtain:

$$
M=\frac{\beta p}{t A_{c}} A K^{\alpha} L^{1-\alpha} w(\varphi)
$$

Finally, substituting Equation (14) into Equation (13), the labor demand under the condition of embeddedness in the GEVC is:

$$
L=\left[\frac{Z}{A K^{\alpha} w(\varphi)}\right]^{\frac{1}{1-\alpha}}
$$

Equation (15) shows that the labor demand of developing countries embedded in the GEVC is affected by factors such as technology level, input capital factors, and the degree of embeddedness of enterprises. Moreover, as the embeddedness of developing countries in the GEVC continues to increase, the demand for labor may decline.

\section{Index measurement and model setting}

(1) Measurement of the degree of embeddedness of enterprises in the GEVC

The foreign value-added rate of enterprise exports proposed by Upward et al. (2013) is the most popular measurement of global value chain embeddedness at the micro level. Its basic formula is:

$$
F V A R=\frac{F V A}{X}=\frac{M^{P}+X^{o}\left(M^{o} /\left(D+X^{o}\right)\right)}{X}
$$

where FVAR refers to the foreign value-added rate of enterprise exports; $M, X$, and $D$ represent the import, export, and domestic sales values of an enterprise, respectively; and superscripts $p$ and $o$ represent processing trade and general trade, respectively. This measurement method assumes that goods imported by general trade are used in the same proportion in domestic sales and international exports, so the calculation results are relatively rough. Taking into account China's actual trade situation, we modify the definition of intermediate products in general trade and the domestic composition of intermediate inputs by referring to the processing methods of scholars such as Kee and Tang (2016). The adjusted equation is:

$$
D V A R=1-\frac{F V A_{F}}{X}=1-\frac{M^{p}+X^{o}\left(M_{m}^{o} /\left(D+X^{o}\right)\right)+0.1\left\{M^{T}+M^{p}+\delta_{k}^{F}\left[M_{m}^{o} /\left(D+X^{o}\right)\right]\right\}}{X}
$$

where DVAR represents the domestic value-added rate of enterprise exports; $M_{m}^{o}$ represents the intermediate goods, excluding local consumption and capital goods; and $M^{T}$ represents the 
The domestic value-added rate of enterprise exports only considers the economic benefits obtained by enterprises in global value chains; it ignores the environmental costs. Therefore, we measure the carbon, energy, and pollution footprints at the industry level and monetize the ecological footprint based on the idea of ecological compensation to measure the environmental cost of the embeddedness of enterprises in the global value chain. The equations for calculating the carbon, energy, and pollution footprints are as follows:

$$
C_{i}=\sum_{i=1}^{8} E_{j t} \times T_{j} \times C_{j} \times R_{j} \times \frac{44}{12}
$$

$$
E F_{C i}=E F_{C i f}+E F_{C i g}=\frac{C_{i} \times P_{f}}{E P_{f}}+\frac{C_{i} \times P_{g}}{E P_{g}}
$$

$$
\begin{aligned}
& E F_{E i}=\sum_{j=1}^{8} E_{i j} \times M_{j} \\
& E F_{P i}=\sum_{i=1}^{4} L_{i} / D_{i}
\end{aligned}
$$

where $E F_{C i}, E F_{E i}$, and $E F_{P i}$ represent the carbon, energy, and pollution footprints, respectively. The variable $t$ represents the year; and $j$ represents energy, of which there are eight kinds (i.e., raw coal, coke, kerosene, crude oil, gasoline, diesel, fuel oil, and natural gas). $E$ refers to the level of consumption, $T$ represents the calorific conversion coefficient, $C$ is the carbon oxidation factor, and $R$ is the default carbon content. $E P_{f}=3.8096 t / \mathrm{hm}^{2}$, representing the global average carbon absorption capacity of forests; $E P_{g}=0.9482 \mathrm{t} / \mathrm{hm}^{2}$, representing the global average carbon absorption capacity of grassland; and $M_{j}$ is the land area occupied by 1 ton of fossil energy (1kwh of electricity). $i, L$, and $M_{j}$ refer to pollutants, emissions, and the absorption capacity of the land, respectively. The relevant data can be obtained from the China Energy Statistical Yearbook and IPCC National Greenhouse Gas Inventory Guidelines 2006.

The equation of ecological compensation at the enterprise level is:

$$
E C=e c \times\left(E F c+E F_{E}+E F_{P}\right)
$$

where $E F c, E F_{E}$, and $E F_{P}$ represent the carbon, energy, and pollution footprints of a single enterprise, respectively, which can be obtained from the ecological footprint at the industry level according to the ratio of the fixed assets or sales output of the enterprise to the fixed capital or sales output of the industry. ec represents the amount of ecological compensation per unit of ecological footprint, which is calculated as the ratio of the total annual ecological compensation to the ecological footprint.

Based the "Cost of Pollution in China" report jointly released by the World Bank and the Development Research Center of the State Council of China in 2007, we set $5.8 \%$ of the annual 
GDP as the total amount of ecological compensation for that year. After the above adjustments, the equation of the degree of embeddedness in the GEVC is as follows:

$$
e D V A R=D V A R-\frac{E C}{X}
$$

where $e D V A R$ represents the export domestic value-added rate of enterprises considering environmental costs, that is, the degree of enterprise embeddedness in the GEVC.

(2) Econometric model setting

In order to study the impact of GEVC embedding on employment, this study takes the scale of employment as the explained variable and the degree of embeddedness of enterprises in the GEVC as the core explanatory variable to establish the following econometric model:

$$
\ln l a b_{i t}=\beta_{0}+\beta_{1} \times \ln e D V A R_{i t}+\gamma_{i} \sum X_{j i t}+\lambda_{i}+v_{t}+\varepsilon_{i t}
$$

where $i$ refers to the enterprise, $t$ describes the year, and lnlab represents the logarithm of the number of employees. IneDVAR represents the logarithm of the degree of embeddedness of enterprises in the GEVC; $\lambda_{i}$ and $v_{t}$ refer to the individual fixed effect and time fixed effect, respectively; and $\varepsilon_{i t}$ is the random disturbance term. $X_{j i t}$ refers to other control variables that affect the number of employees in enterprises.

Total factor productivity $(\boldsymbol{t} \boldsymbol{f} \boldsymbol{p})$. Total factor productivity reflects the technological level of enterprises and can indicate the impact of technological progress on the scale of employment. Technological progress has both a negative substitution effect and a positive creation effect on employment. The improvement of enterprises' technological level may lead to the substitution effect of technology, which reduces the demand for labor (Vienneau, 2019). Conversely, technological progress can stimulate consumption and investment demand by reducing product costs and increasing income, thus expanding employment opportunities (Bode et al., 2019). This paper uses the ACF method to measure total factor productivity, and the estimated coefficient of this variable cannot be determined.

Capital intensity $(\ln \boldsymbol{k l})$. The capital intensity index is expressed by the logarithm of the ratio of capital factors to labor factors, which reflects the impact of the adjustment of the production structure on the number of employees. An increase in the index means an increase in the output of capital-intensive sectors, which is usually accompanied by a decrease in the number of employees. Therefore, the estimated coefficient of capital intensity is negative. In the actual measurement, the average annual balance of the net fixed assets of the enterprise is used to represent the capital factor, and the number of employees of the enterprise represents the labor factor.

Import intensity of intermediate products (imp). Generally speaking, the import of intermediate goods will have a substitution effect on domestic employment, which is not conducive to overall employment growth. The import intensity of intermediate products is 
expressed by the proportion of total imported intermediate products in the sales costs of the primary business, and the estimated coefficient is negative.

Enterprise age (age). The age of an enterprise can reflect the operating conditions of an enterprise from an outside perspective. Generally, the longer an enterprise survives, the better the operating conditions and the more labor it can absorb. The age of the enterprise is expressed as the current year minus the year of establishment plus one, and the estimated coefficient is positive.

Enterprise size (scal). According to the average value of the income from the primary business, we divide the enterprises into two categories: large-scale enterprises and small-scale enterprises, which are introduced by dummy variables. Generally speaking, the larger the enterprise, the more labor it will absorb, so the coefficient of this variable is also expected to be positive.

(3) Data specification

The research data used in this paper are mainly from China Industrial Enterprise Database and China Customs Import and Export Trade Database, and the research sample interval is limited from 2000 to 2006. High-quality data are the premise and basis for empirical analysis. The China Industrial Enterprise Database is compiled based on the data obtained from the "statistics of industrial statistics statements above designated size" conducted by the National Bureau of Statistics, covering about $95 \%$ of Chinese industrial enterprises, and its data quality is well guaranteed. The data published in this database is up to 2013. However, there is a lack of intermediate input index in the database of Chinese industrial enterprises after 2007, which makes it impossible to accurately calculate the domestic added value of enterprises embedded in the value chain. Therefore, most of the recently published high-quality studies using data at the micro level in China limit the research range to before 2007 (Brandt et al., 2019).

The China Customs Import and Export Trade Database contains records of foreign trade import and export transactions between China Customs and other countries and regions, including all commodities classified by country (region) and customs category in 31 provinces (autonomous regions and municipalities) and more than 200 prefecture-level units in China. The quantity of imports and exports can be used to study the international trade behavior of Chinese enterprises. The data from China Customs is monthly data, so we first aggregate the monthly data to the annual level, and then, we use the "two-step method" to merge the two databases, following Yu (2015). After that, we filter and sort the merged data to obtain the sample for this study. The statistical description information is shown in Table 1.

Insert Table 1 here

\section{Empirical analysis}
(1) Baseline regression analysis 

controlling for the individual fixed effect and time fixed effect, the estimated coefficient of the degree of embeddedness of enterprises in the GEVC is significantly negative at the $1 \%$ level, which is consistent with our expectations. In order to avoid the impact of omitted variables on the regression results, we re-run the regression with the addition of control variables; the results are shown in Column (2) of Table 2. It can be seen that after adding the control variables, the estimated coefficient of the main explanatory variable, GEVC embeddedness, is still significantly negative at the $1 \%$ significance level, indicating that an increase in the degree of embeddedness of enterprises in the GEVC will inhibit the growth of the employment scale. This may be because with the continuous improvement in the degree of embeddedness of enterprises in the GEVC, enterprises have gradually shifted from labor-intensive processing equipment links to capital-intensive and technology-intensive links, thereby reducing the demand for labor factors. Moreover, enterprises with a higher degree of GEVC embeddedness have better and cleaner production technology, as well as a higher level of automation and intelligence, which may also

For the comparison with traditional trade, we examine the impact of export intensity (ex) on the scale of employment in Columns (3) and (4) of Table 2. The export intensity index is expressed by the ratio of export delivery value to industrial sales output value. The results show that an increase in export intensity can significantly promote the expansion of the scale of employment, mainly because with increased exports, enterprises must employ more workers to meet the production demand, which brings a positive effect to the labor market. In terms of control variables, the coefficient of total factor productivity is significantly negative, indicating that the negative substitution effect of technological progress on employment is greater than the positive creation effect, reflecting a reduced demand for labor. The coefficients of capital intensity and of import intensity of intermediate goods are significantly negative, indicating that enterprises with high capital intensity and high import intensity of intermediate goods absorb less labor, which is in line with expectations. The coefficients of enterprise age and enterprise size are significantly positive, indicating that the more established and larger the enterprise, the greater the demand for labor, which is also consistent with expectations.

(2) Potential endogeneity analysis

In order to avoid the interference of endogeneity with respect to the estimation results, this analysis uses two instrumental variables, the lagged term of GEVC embeddedness and the average tariff at the enterprise level to conduct the endogeneity test. The tariff level of enterprises' imports 
is closely related to the degree of embeddedness of enterprises in the GEVC, but it is not directly related to the scale of employment. The tariff level of enterprises' imports is expressed by the import-weighted average tariff level of enterprises $(\mathrm{iwad})$. The specific formula is as follows:

$$
\operatorname{iwad}_{i t}=\ln \left(\sum_{n=1}^{m} A g^{H S \sigma} \times \operatorname{Value}_{i t}^{H S \sigma} / T V_{i t}\right)
$$

where $A g^{H S 6}$ represents the average tariff level of goods under the HS 6-digit code used by China Customs. Value stands for the value of goods; $T V$ represents the total amount of imports; $m$ refers to the category of imported goods. The data are taken from the World Tariff Database.

Columns (1) and (2) of Table 3, respectively, report the results of two-stage least squares (2SLS) regression using the lagged term of the degree of GEVC embeddedness and the average corporate tariff as instrumental variables. The regression results show that the core explanatory variable, GEVC embeddedness, has a significant negative impact on the employment scale. The F-values of the weak instrument test are all large, indicating that there is no weak instrument variable problem. Compared with the baseline regression results in Table 2, the coefficients of each variable have not changed, and the absolute value of each variable has increased. This supports the validity of the conclusion that an improvement in the degree of embeddedness of enterprises in the GEVC would inhibit the expansion of the scale of employment.

\section{Insert Table 3 here}

(3) Heterogeneity analysis

1. Differences in the impact of GEVC embeddedness on the employment of laborers of different genders

In the initial stage of the development of the division of labor system within the value chain, more employment opportunities are created for women in developing countries. In particular, the processing and manufacturing industries focused on the export of electronic products attract a large number of female workers (Osterreich, 2020). When the degree of embeddedness of enterprises in the GEVC increases, the impact on workers may be heterogeneous based on gender. Therefore, this study further examines the impact of GEVC embeddedness on female and male employees, as shown in Columns (1) and (2) of Table 4. The results show that with the improvement in the degree of GEVC embeddedness, enterprises' demand for female and male employees decreases, and the impact on women is greater than that on men. This may be because women are generally less educated than men in China, and the cost of maternity, labor protection, and special care for female employees increases the financial burden on the enterprise. Therefore, when the degree of GEVC embeddedness of enterprises increases, the female members of the labor force will be more adversely affected. 
2. Differences in the impact of GEVC embeddedness on the employment of laborers with different skill levels

At different stages of embeddedness in the GEVC, enterprises have different requirements in relation to the skill distribution of the labor force. Therefore, it is necessary to test whether there are differences in the impact of GEVC embeddedness on the employment of laborers with different skills. Columns (3) and (4) of Table 4, respectively, report the impact of GEVC embeddedness on mid- and highly-skilled employees as well as lower-skilled employees. The results show that the increase in the degree of embeddedness of enterprises in the GEVC inhibits the enterprise's demand for employees of all skill levels, but the inhibitory effect on the employment of lower-skilled employees is greater. This may be because management and technical personnel with higher knowledge and skills are needed in the promotion of management and R\&D innovation, which can enhance the profitability of enterprises in the GEVC. Thus, higher-skilled employees are less exposed to unemployment risk.

\section{Insert Table 4 here}

3. Differences in the impact of the GEVC embeddedness of enterprises under different ownership structures on employment

In the GEVC embedding process, the value chain network connection between foreign-funded enterprises and multinational corporations has natural advantages that are significantly different from those of state-owned and domestically owned private enterprises. This may cause differences in the impact of GEVC embeddedness on the scale of employment. Therefore, this study distinguishes the types of enterprise ownership for further regression testing. The regression results of state-owned enterprises, private enterprises, and foreign-funded enterprises are shown in Columns (1), (2) and (3) of Table 5, respectively. The results show that with the increase in the degree of GEVC embeddedness, the level of employment for state-owned enterprises and private enterprises drops significantly, while the impact for foreign-funded enterprises is not significant. This may be because foreign-funded enterprises can gain advanced technology and management knowledge through the foreign direct investment of multinational companies, thereby improving their position in the GEVC with a relatively small technical cost and reducing the impact on labor input factors.

4. Differences in the impact of the degree of GEVC embeddedness in different regions on employment

Levels of economic development and factor endowments vary by region, and this may affect the impact of enterprises' level of GEVC embeddedness on employment. Therefore, this study divides 
the total sample into two regional groupings, the eastern region and the combined central and western regions, to analyze the impact of GEVC embeddedness on employment. The results in Columns (4) and (5) of Table 5 show that an increase in enterprises' degree of embeddedness in the GEVC has a significant negative impact on employment in the eastern region, while the impact on employment in the central and western regions is not significant. This may be because the level of environmental regulation and labor costs in the eastern region are relatively high. When the degree of embeddedness in the GEVC increases, investments in pollution control further squeeze the labor input factors and reduce the demand for labor.

\section{Insert Table 5 here}

\section{Analysis of the influencing mechanism}

The baseline regression results show that the increase in the degree of embeddedness of enterprises in the GEVC has a significant negative impact on the scale of employment, while the heterogeneity test results show that the impacts vary widely according to employee gender and skill level as well as enterprise ownership type and regional location. Together, these results indicate that the effect on employment will be influenced through three channels: the cost increase effect, the innovation promotion effect, and the foreign direct investment effect. Therefore, we establish the following model to test the influence mechanism:

$$
\ln l a b_{i t}=\beta_{0}+\beta_{1} \ln e D V A R_{i t}+\beta_{2}{\ln e D V A R_{i t} \times e f f}_{i t}+\beta_{3} e f f_{i t}+\gamma_{i} \sum X_{j i t}+\lambda_{i}+v_{t}+\varepsilon_{i t}(26)
$$

where eff represents one of the three different influencing mechanisms. The product term of IneDVAR and eff reflects the interaction of the different mechanisms on employment. This study uses wage level per capita (lnwag), the R\&D level of enterprises $(R D)$, and foreign direct investment $(f d i)$, to test the cost increase effect, innovation promotion effect, and foreign direct investment effect, respectively. Wage level per capita is expressed by the logarithm of the average annual salary of employees of the enterprise. The $R \& D$ level of the enterprise is expressed by the ratio of the output value of new products to the industrial sales output value of the same year. Foreign direct investment is expressed by the share of foreign capital in the paid-in capital of the enterprise. Table 6 reports the test results of the influence mechanism.

\section{Insert Table 6 here}

According to the results in Column (1) of Table 6, the coefficient of interaction between the degree of GEVC embeddedness and wage level per capita is significantly negative, indicating that an increase in the wage level per capita enhances the negative effect of GEVC embeddedness on 
the employment scale. Wage expenditure is the main labor cost of an enterprise, and it directly affects the total operating cost of an enterprise embedded in GEVC. When the enterprise climbs to the middle and high end of the GEVC, the excessively high labor costs will further reduce the labor demand of the enterprise and enhance the negative impact of the degree of GEVC embeddedness on the employment scale.

The results in Column (2) show that the coefficient of the interaction term between the degree of GEVC embeddedness and the R\&D level of enterprises is significantly positive, indicating that an increase in the R\&D level will mitigate the adverse impact of an improvement in the degree of GEVC embeddedness on employment. As the degree of embeddedness continues to increase, the R\&D demand of enterprises also increases. This, in turn, drives enterprises' demand for medium and high-skilled labor and reduces the negative effect of GEVC embeddedness on employment.

The results in Column (3) show that the coefficient of the interaction term between GEVC embeddedness and foreign direct investment is significantly positive at the $1 \%$ level, indicating that the higher the level of foreign direct investment, the smaller the negative impact of GEVC embeddedness on employment. Enterprises in developing countries can use foreign direct investment channels to invest in learning in order to leverage the advanced technology and management experience of multinational companies and improve their position in the GEVC, thereby weakening the adverse impact of GEVC embedding on employment.

\section{Conclusion and policy implications}

This study uses 2000-2006 data from the China Industry Business Performance and China Customs databases to examine the relationship between the degree of enterprise embeddedness in the GEVC and the level of employment at a micro level. It also analyzes the heterogeneity of the impact on employment based on gender, skill level, enterprise ownership type, and geographic location. Based on the analysis, we conclude that the increase in the degree of GEVC embeddedness will have a negative impact on the level of employment. This conclusion remains stable even after considering any potential endogeneity problems. Our findings show that the increase in GEVC embeddedness has a greater negative impact on female and lower-skilled employees, employees of state-owned and private enterprises, as well as those located in the eastern region. However, the impact on foreign-funded enterprises and those based in the central and western regions is not significant. The employment effect of GEVC embedding is affected by the cost increase effect, the innovation promotion effect, and the foreign direct investment effect. The cost increase effect enhances the negative effect of GEVC embedding on employment, while the innovation promotion effect and foreign direct investment effect can reduce it. 
The conclusions presented in this paper provide a reference for developing countries seeking to effectively protect people's livelihood and employment while achieving a leap in the division of labor along the green value chain. It is an inevitable choice for China's economic and trade development to continuously promote the division of labor within the value chain as it moves from being a labor-intensive production link to becoming a low-pollution, high-value-added capital- and technology-intensive link.

In view of the frictional and structural unemployment problems that may arise from the rise of enterprises in the GEVC, we should attach importance to the domestic market and give play to the positive role of the domestic value chain in promoting employment, which can effectively alleviate the employment pressure in China. The government should first improve the construction of the factor market and industrial chain infrastructure to promote the free flow of labor and other factors domestically. Second, based on the difference in cost sensitivity between coastal and inland areas, the government should actively guide the eastern coastal areas to engage in the high-end links of the value chain, such as design, $R \& D$, and sales, while encouraging the central and western inland areas to engage in the low-end links of the value chain, such as processing equipment, to gradually promote the development and improvement of the domestic value chain. Finally, the dual cycle of the domestic value chain and the global value chain should be relied upon to drive the development of related industries. In this way, we can realize the scale effect of the domestic market and promote domestic employment.

With the in-depth development of the division of labor along the value chain and the continuous adjustment of the industrial structure, the traditional quantity advantage of the labor force in China is gradually disappearing. Only by improving the quality and efficiency of the labor force can people's living standards be truly improved and the fruits of environmentally conscious and open development be shared more broadly. Therefore, the government should appropriately increase the fiscal budget to broaden the scope of education and improve the efficiency of the use of education expenditures. Meanwhile, the government should strengthen public service guarantee systems such as vocational training, to improve the speed and quality of human capital accumulation and provide high-quality technical and managerial talent for both China's domestic value chain and the GEVC. This will help to guarantee the stability of the domestic employment market. In addition, the government should support female employment and share the labor costs of enterprises by improving the maternity insurance system and increasing maternity subsidies.

Independent innovation is the key force to promote the transformation and upgrading of industrial enterprises, and it also drives the rising status of enterprises in the GEVC. Therefore, the government should guide and encourage enterprises to continuously improve their independent innovation and R\&D capabilities and promote the transformation of the technological catch-up 
model from "introduction and imitation" to independent innovation. In this way, China can gradually transform from a contracted country to a contracting country, which can allow enterprises to play an increasingly important role in solving employment problems.

501 The impact of foreign direct investment on employment cannot be ignored. It is important to pay attention to the investment regions and industries attracting foreign direct investment. The government can guide the flow of foreign capital to the central and western regions where economic development is relatively weak, thereby promoting the extension and growth of the value chain in these areas. At the same time, this will reduce the impact of foreign investment on enterprises in the eastern region, broaden employment channels, and improve the scale and quality of employment.

Based on the perspective of environmental cost, this paper explores the relationship between GVC embeddedness and labor employment and its influence mechanism at the micro level. However, limited by the openness of data, this paper cannot carry out a prospective analysis on the latest value chain embeddedness and employment issues at the enterprise level at this stage. In addition, when measuring the environmental costs of enterprises embedded in GVCs, due to the difficulty in obtaining enterprise-level pollution data in the full sample, we first calculate the ecological footprint at the industry level, and then calculate the environmental costs at the enterprise level in the form of capital ratio or output value ratio. Although this method can realize environmental cost accounting at the enterprise level under the existing data conditions, it fails to consider the heterogeneity of enterprises and ignores the role of environmental regulation, technology and economy in different regions. With the improvement of the availability of more microscopic and detailed enterprise-level data, we will further break through these problems in subsequent studies. 

makes the conclusions and submit the article. no. 14ZDB151).

Data availability: The data used during the current study are available from the corresponding author on reasonable request.

\section{$529 \quad$ Compliance with ethical standards}

530 Conflict of interest: The authors declare that they have no conflict of interest.

Ethical approval: Ethical approval was obtained from the National Natural Science Foundation of China.

533 Consent to participate: All authors of the article consent to participate.

534 Consent to publish: All authors of the article consent to publish. 


\section{References}

Amare, M., Mariara, J. Oostendorp, R. \& Pradhan, M. 2019. The impact of smallholder farmers' participation in avocado export markets on the labor market, farm yields, sales prices, and incomes in Kenya. Land Use Policy, 88:1-13.

Antweiler, W., Copeland, B.R. \& Taylor, M.S. 2001. Is free trade good for the environment? American Economic Review, 91: 877-908.

Bode, E., Brunow, S., Ott, I. \& Sorgner, A. 2019. Worker personality: Another skill bias beyond education in the digital age. German Economic Review, 20(4):254-294.

Brandt, L.J. Van Biesebroeck, J. Wang, L.H. \& Zhang, Y.F. 2019. WTO Accession and performance of Chinese manufacturing firms: Corrigendum. American Economic Review, 109(4): 1616-1621.

Chang, T.Y., Zivin, J.G., Gross, T. \& Neidell, M. 2019. The effect of pollution on worker productivity: Evidence from call center workers in China. American Economics Journal-Applied Economics, 11(1):151-172.

Feenstra, R.C. \& Hanson, G.H. 1996. Globalization, outsourcing, and wage inequality. National Bureau of Economic Research, 86(2):1-13.

Fei, R. Pan, A., Wu, X. 2020. How GVC division affects embodied carbon emissions in China's exports? Environmental Science and Pollution Research, 27(29): 36605-36620.

Kaplan, L.C., Kohl, T. \& Martinez-Zarzoso, I. 2018. Supply-chain trade and labor market outcomes: The case of the 2004 European Union enlargement. Review of International Economics, 26(2):481-506.

Kee, H.L. \& Tang, H. 2016. Domestic value added in exports: Theory and firm evidence from China. American Economic Review, 106(6):1402-1436.

Li, X.Y. \& Zhou, Y. 2017. Offshoring pollution while offshoring production? Strategic Management Journal, 38:2310-2329.

Li, G., Li, L., Choi, T.M. \& Sethi, S. P. 2019. Green supply chain management in Chinese firms: Innovative measures and the moderating role of quick response technology. Journal of Operations Management (Online).

Lopez, L.A., Cadarso, M.A., Zafrilla, J. \& Arce, G. 2019. The carbon footprint of the US multinationals' foreign affiliates. Nature Communications, 10(1):1-24.

Mangla, S.K., Luthra, S., Mishra, N., Singh, A. \& Rana, N.P. et al. 2018. Barriers to effective circular supply chain management in a developing country context. Production Planning \& Control, 29(6): 551-569. 
Masso, J. \& Vahter, P. 2019. Knowledge transfer from multinationals through labour mobility: Are there effects on productivity, product sophistication and exporting? Emerging Markets Finance and Trade, 55(12): 2774-2795.

Meng, J., Mi, Z.F., Guan, D.B., Li, J.S. \& Tao, S. et al. 2018. The rise of South-South trade and its effect on global CO2 emissions. Nature Communications, 9(1):1-8.

Narula, R. 2019. Enforcing higher labor standards within developing country value chains: Consequences for MNEs and informal actors in a dual economy. Journal of International Business Studies, 50(9):1622-1635.

Osterreich, S.T. 2020. Gender, decent work, and global production sharing in Indonesian manufacturing. Journal of Economics issues, 54(1):54-76.

Pahl, S. \& Timmer, M.P. 2020. Do global value chains enhance economic upgrading? A long view. Journal of Development Studies, 56(9):1683-1705.

Reijnders, L.S.M. \& de Vries, G.J. 2018. Technology, offshoring and the rise of non-routine jobs. Journal of Development Economics, 135:412-432.

Upward, R., Wang, Z. \& Zheng, J. 2013. Weighing China's export basket: The domestic content and technology intensity of Chinese exports. Journal of Comparative Economics, 41(2): $527-543$.

Vienneau, R.L. 2019. Structural economic dynamics, markups, real Wicksell effects, and the reverse substitution of labor. Structural Change and Economic Dynamics, 50:216-226.

Wang, P., Kinnucan, H.W. \& Duffy, P.A. 2019a. The effects of rising labour costs on global supply chains: The case of China's cotton yarn industry. Applied Economics, 51(33):3608-3623.

Wang, S.H., Li, Z.Z. \& Song M. 2019b. How embodied carbon in trade affects labor income in developing countries. The Science of the Total Environment, 672:71-80.

Wang, S.H., Li, Z.Z, Zhang, H.Y. 2021. Does female labor share reduce embodied carbon in trade? Environmental Science and Pollution Research. 28(7): 8246-8257.

Yu, M.J. 2015. Processing trade, tariff reductions and firm productivity: Evidence from Chinese firms. Economic Journal, 12(585):943-988. 
Table 1 Statistical description of main variables

\begin{tabular}{|c|c|c|c|c|c|c|}
\hline Variable & Obs & Mean & Std. Dev. & Min & Max & $\begin{array}{c}\text { Estimated } \\
\text { coefficient }\end{array}$ \\
\hline lnlab & 54124 & 5.729 & 1.135 & 1.386 & 11.964 & - \\
\hline lneDVAR & 33442 & -0.671 & 0.710 & -8.454 & -0.002 & - \\
\hline tfp & 54124 & 2.711 & 1.039 & -5.096 & 10.078 & - \\
\hline Inkl & 54124 & 3.779 & 1.379 & -6.354 & 14.258 & - \\
\hline imp & 54114 & 0.502 & 30.483 & 0 & 7079.442 & + \\
\hline age & 54124 & 11.505 & 20.907 & 1 & 2001 & + \\
\hline scal & 54124 & .0153 & 0.360 & 0 & 1 & + \\
\hline
\end{tabular}

600

601 
Table 2 Baseline regression results

\begin{tabular}{|c|c|c|c|c|}
\hline \multirow{2}{*}{ Variables } & \multicolumn{4}{|c|}{ lnlab } \\
\hline & (1) & (2) & (3) & (4) \\
\hline lneDVAR & $\begin{array}{c}-0.0148^{* * * *} \\
(0.0044)\end{array}$ & $\begin{array}{l}-0.0210^{* * * *} \\
(0.0039)\end{array}$ & & \\
\hline ex & & & $\begin{array}{c}0.0594^{* * *} \\
(0.0085)\end{array}$ & $\begin{array}{c}0.0412^{* * * *} \\
(0.0076)\end{array}$ \\
\hline $\mathrm{tfp}$ & & $\begin{array}{c}-0.1135^{* * *} \\
(0.0034)\end{array}$ & & $\begin{array}{c}-0.1019^{* * * *} \\
(0.0025)\end{array}$ \\
\hline lnkl & & $\begin{array}{c}-0.2997^{* * * *} \\
(0.0037)\end{array}$ & & $\begin{array}{c}-0.2934^{* * * *} \\
(0.0028)\end{array}$ \\
\hline imp & & $\begin{array}{c}-0.0004^{* * *} \\
(0.0001)\end{array}$ & & $\begin{array}{c}-0.0004^{* * * *} \\
(0.0000)\end{array}$ \\
\hline age & & $\begin{array}{c}0.0005^{* * *} \\
(0.0001)\end{array}$ & & $\begin{array}{c}0.0003^{\text {**** }} \\
(0.0001)\end{array}$ \\
\hline scal & & $\begin{array}{c}0.3657^{* * *} \\
(0.0116)\end{array}$ & & $\begin{array}{c}0.3539^{* * *} \\
(0.0078)\end{array}$ \\
\hline _cons & $\begin{array}{l}5.5052^{* * *} \\
(0.0066)\end{array}$ & $\begin{array}{l}6.7997^{* * *} \\
(0.0180)\end{array}$ & $\begin{array}{l}5.5227^{* * *} \\
(0.0063)\end{array}$ & $\begin{array}{c}6.8557^{* * *} \\
(0.0146)\end{array}$ \\
\hline Individual fixed & Yes & Yes & Yes & Yes \\
\hline Time fixed & Yes & Yes & Yes & Yes \\
\hline$N$ & 33442 & 33436 & 58147 & 58136 \\
\hline $\mathrm{r} 2$ & 0.056 & 0.262 & 0.060 & 0.256 \\
\hline $\mathrm{F}$ & 231.897 & 802.204 & 451.801 & 1429.525 \\
\hline $\mathrm{p}$ & 0.000 & 0.000 & 0.000 & 0.000 \\
\hline
\end{tabular}

603

Note: The values between parentheses are the standard errors of regression coefficients. ***, **, and * indicate 604 significance at the $1 \%, 5 \%$ and $10 \%$ levels, respectively. 
Table 3 2sls regression results

\begin{tabular}{|c|c|c|}
\hline \multirow{2}{*}{ Variables } & L.lneDVAR & iwad \\
\cline { 2 - 3 } & $(1)$ & $(2)$ \\
\hline \multirow{2}{*}{ lneDVAR } & $-0.3186^{* * *}$ & $-0.7547^{* * *}$ \\
& $(0.1012)$ & $(0.1517)$ \\
\hline \multirow{2}{*}{ tfp } & $-0.1122^{* * *}$ & $-0.1063^{* * *}$ \\
& $(0.0041)$ & $(0.0053)$ \\
\hline \multirow{2}{*}{ lnkl } & $-0.3378^{* * *}$ & $-0.3191^{* * *}$ \\
\hline \multirow{2}{*}{ imp } & $(0.0056)$ & $(0.0069)$ \\
\hline \multirow{2}{*}{ age } & $-0.0520^{* * *}$ & $-0.0005^{* * *}$ \\
& $(0.0254)$ & $(0.0001)$ \\
\hline \multirow{2}{*}{ scal } & $0.0027^{* * *}$ & 0.0000 \\
& $(0.0005)$ & $(0.0002)$ \\
\hline Individual fixed & $0.3140^{* * *}$ & $0.3398^{* * *}$ \\
\hline Time fixed & $(0.0143)$ & $(0.0183)$ \\
\hline$N$ & Yes & Yes \\
\hline r2 & Yes & Yes \\
\hline F & 25405 & 32894 \\
\hline The & 0.170 & -0.684 \\
\hline & 631.173 & 352.655 \\
\hline
\end{tabular}

Note: The values between parentheses are the standard errors of regression coefficients. ${ }^{* * *},{ }^{* *}$, and $*$ indicate 608 significance at the $1 \%, 5 \%$ and $10 \%$ levels, respectively. 
Table 4 Regression results for employees of different genders and with different skill levels

\begin{tabular}{|c|c|c|c|c|}
\hline \multirow{2}{*}{ Variables } & Female employees & Male employees & Middle-and high-skilled & Junior-skilled \\
\hline & (1) & (2) & (3) & (4) \\
\hline \multirow{2}{*}{ lneDVAR } & $-0.0215^{* * *}$ & $-0.0210^{* * *}$ & $-0.0190^{* * * *}$ & $-0.0224^{* * *}$ \\
\hline & $(0.0039)$ & $(0.0039)$ & $(0.0047)$ & $(0.0045)$ \\
\hline \multirow{2}{*}{$\operatorname{tfp}$} & $-0.1129^{* * * *}$ & $-0.1135^{* * *}$ & $-0.1163^{* * *}$ & $-0.1149^{* * * *}$ \\
\hline & $(0.0034)$ & $(0.0034)$ & $(0.0042)$ & $(0.0041)$ \\
\hline \multirow{2}{*}{ lnkl } & $-0.3007^{* * *}$ & $-0.2997^{* * *}$ & $-0.2970^{* * *}$ & $-0.2804^{* * *}$ \\
\hline & $(0.0037)$ & $(0.0037)$ & $(0.0047)$ & $(0.0046)$ \\
\hline \multirow{2}{*}{ imp } & $-0.0004^{* * *}$ & $-0.0004^{* * *}$ & $-0.0004^{* * * *}$ & $-0.0004^{* * *}$ \\
\hline & $(0.0001)$ & $(0.0001)$ & $(0.0001)$ & $(0.0001)$ \\
\hline \multirow{2}{*}{ age } & $0.0005^{* * *}$ & $0.0005^{* * *}$ & $0.0043^{* * *}$ & $0.0006^{* * *}$ \\
\hline & $(0.0001)$ & $(0.0001)$ & $(0.0005)$ & $(0.0002)$ \\
\hline \multirow{2}{*}{ scal } & $0.3660^{* * *}$ & $0.3657^{* * *}$ & $0.3447^{* * *}$ & $0.3445^{* * *}$ \\
\hline & $(0.0116)$ & $(0.0116)$ & $(0.0126)$ & $(0.0129)$ \\
\hline \multirow{2}{*}{ _cons } & $6.0873^{* * *}$ & $6.8011^{* * * *}$ & $3.2545^{* * * *}$ & $3.6564^{* * *}$ \\
\hline & $(0.0180)$ & $(0.0180)$ & $(0.0238)$ & $(0.0224)$ \\
\hline Individual fixed & Yes & Yes & Yes & Yes \\
\hline Time fixed & Yes & Yes & Yes & Yes \\
\hline$N$ & 33338 & 33436 & 21769 & 22811 \\
\hline $\mathrm{r} 2$ & 0.263 & 0.262 & 0.272 & 0.248 \\
\hline $\mathrm{F}$ & 806.004 & 802.204 & 547.513 & 507.059 \\
\hline $\mathrm{p}$ & 0.000 & 0.000 & 0.000 & 0.000 \\
\hline
\end{tabular}

611

Note: The values between parentheses are the standard errors of regression coefficients. ***, **, and * indicate 612 significance at the $1 \%, 5 \%$ and $10 \%$ levels, respectively. 
Table 5 Regression results for enterprises of different ownerships and regions

\begin{tabular}{|c|c|c|c|c|c|}
\hline \multirow{2}{*}{ Variables } & State-owned & Private & Foreign-funded & East & Middle and west \\
\hline & (1) & (2) & (3) & (4) & (5) \\
\hline \multirow{2}{*}{$\operatorname{lnDVAR}$} & $-0.0554^{* * *}$ & $-0.0411^{* * * *}$ & 0.0096 & $-0.0215^{* * *}$ & -0.0145 \\
\hline & $(0.0201)$ & $(0.0116)$ & $(0.0065)$ & $(0.0040)$ & $(0.0180)$ \\
\hline \multirow{2}{*}{$\mathrm{tfp}$} & $-0.1080^{* * * *}$ & $-0.1358^{* * *}$ & $-0.1109^{* * * *}$ & $-0.1144^{* * *}$ & $-0.0905^{* * *}$ \\
\hline & $(0.0173)$ & $(0.0118)$ & $(0.0052)$ & $(0.0035)$ & $(0.0140)$ \\
\hline \multirow{2}{*}{$\operatorname{lnkl}$} & $-0.5181^{* * *}$ & $-0.2836^{* * *}$ & $-0.2894^{* * *}$ & $-0.3035^{* * *}$ & $-0.2230^{* * * *}$ \\
\hline & $(0.0246)$ & $(0.0111)$ & $(0.0060)$ & $(0.0038)$ & $(0.0169)$ \\
\hline \multirow{2}{*}{ imp } & -0.0108 & $-0.0742^{*}$ & 0.0035 & $-0.0004^{* * *}$ & 0.0208 \\
\hline & $(0.0103)$ & $(0.0402)$ & $(0.0026)$ & $(0.0001)$ & $(0.0254)$ \\
\hline \multirow{2}{*}{ age } & $0.0030^{* *}$ & $0.0028^{* * * *}$ & 0.0003 & $0.0004^{* * *}$ & $0.0084^{* * *}$ \\
\hline & $(0.0015)$ & $(0.0008)$ & $(0.0002)$ & $(0.0001)$ & $(0.0014)$ \\
\hline \multirow{2}{*}{ scal } & $0.2886^{* * *}$ & $0.2973^{* * *}$ & $0.3942^{* * *}$ & $0.3661^{* * *}$ & $0.3690^{* * *}$ \\
\hline & $(0.0587)$ & $(0.0312)$ & $(0.0179)$ & $(0.0119)$ & $(0.0529)$ \\
\hline \multirow{2}{*}{ _cons } & $8.3276^{* * *}$ & $6.5963^{* * *}$ & $6.7496^{* * *}$ & $6.8129^{* * * *}$ & $6.4219^{* * * *}$ \\
\hline & $(0.1407)$ & $(0.0539)$ & $(0.0306)$ & $(0.0184)$ & $(0.0809)$ \\
\hline Individual fixed & Yes & Yes & Yes & Yes & Yes \\
\hline Time fixed & Yes & Yes & Yes & Yes & Yes \\
\hline$N$ & 1084 & 4582 & 13764 & 31714 & 1722 \\
\hline $\mathrm{r} 2$ & 0.4582 & 0.2397 & 0.2862 & 0.2676 & 0.1773 \\
\hline $\mathrm{F}$ & 46.7332 & 84.1852 & 344.9618 & 784.0054 & 24.8177 \\
\hline $\mathrm{p}$ & 0.0000 & 0.0000 & 0.0000 & 0.0000 & 0.0000 \\
\hline
\end{tabular}

615

Note: The values between parentheses are the standard errors of regression coefficients. ***,**, and * indicate 616 significance at the $1 \%, 5 \%$ and $10 \%$ levels, respectively. 
Table 6 Test results of influencing mechanism

\begin{tabular}{|c|c|c|c|}
\hline \multirow{2}{*}{ Variables } & Cost increase effect & Innovation promotion effect & Foreign direct investment effect \\
\hline & (1) & (2) & (3) \\
\hline \multirow{2}{*}{ lneDVAR } & $-0.0100^{*}$ & $-0.0241^{* * *}$ & $-0.0358^{* * *}$ \\
\hline & $(0.0054)$ & $(0.0041)$ & $(0.0047)$ \\
\hline \multirow{2}{*}{ lneDVAR×lnwag } & $-0.0005^{* *}$ & & \\
\hline & $(0.0002)$ & & \\
\hline \multirow{2}{*}{ lnwag } & $-0.0065^{* * *}$ & & \\
\hline & $(0.0003)$ & & \\
\hline \multirow{2}{*}{$\operatorname{lneDVAR} \times \mathrm{RD}$} & & $0.0525^{* * *}$ & \\
\hline & & $(0.0169)$ & \\
\hline \multirow{2}{*}{$\mathrm{RD}$} & & $0.1142^{* * * *}$ & \\
\hline & & $(0.0200)$ & \\
\hline \multirow{2}{*}{ lneDVAR×fdi } & & & $0.0435^{\text {*** }}$ \\
\hline & & & $(0.0080)$ \\
\hline \multirow{2}{*}{ fdi } & & & $0.0337^{* * *}$ \\
\hline & & & $(0.0101)$ \\
\hline \multirow{2}{*}{ tfp } & $-0.0959^{* * *}$ & $-0.1136^{* * *}$ & $-0.1140^{* * *}$ \\
\hline & $(0.0034)$ & $(0.0034)$ & $(0.0034)$ \\
\hline \multirow{2}{*}{ lnkl } & $-0.2791^{* * * *}$ & $-0.3001^{* * * *}$ & $-0.3008^{* * * *}$ \\
\hline & $(0.0037)$ & $(0.0037)$ & $(0.0037)$ \\
\hline \multirow{2}{*}{ imp } & $-0.0004^{* * *}$ & $-0.0004^{* * *}$ & $-0.0056^{* * *}$ \\
\hline & $(0.0001)$ & $(0.0001)$ & $(0.0010)$ \\
\hline \multirow{2}{*}{ age } & $0.0005^{* * *}$ & $0.0005^{* * *}$ & $0.0005^{* * *}$ \\
\hline & $(0.0001)$ & $(0.0001)$ & $(0.0001)$ \\
\hline \multirow{2}{*}{ scal } & $0.3722^{* * *}$ & $0.3647^{* * * *}$ & $0.3656^{* * *}$ \\
\hline & $(0.0114)$ & $(0.0116)$ & $(0.0116)$ \\
\hline \multirow{2}{*}{ _cons } & $6.7768^{* * *}$ & $6.7967^{* * * *}$ & $6.7966^{* * * *}$ \\
\hline & $(0.0178)$ & $(0.0180)$ & $(0.0184)$ \\
\hline Individual fixed & Yes & Yes & Yes \\
\hline Time fixed & Yes & Yes & Yes \\
\hline$N$ & 33436 & 33436 & 33396 \\
\hline $\mathrm{r} 2$ & 0.284 & 0.263 & 0.263 \\
\hline F & 769.329 & 690.737 & 691.509 \\
\hline
\end{tabular}




\begin{tabular}{|c|c|c|c|}
\hline $\mathrm{p}$ & 0.000 & 0.000 & 0.000 \\
\hline \multicolumn{2}{|c|}{ Note: The values between parentheses are the standard errors of regression coefficients. ***, **, and * indicate }
\end{tabular}

622 significance at the $1 \%, 5 \%$ and $10 \%$ levels, respectively. 